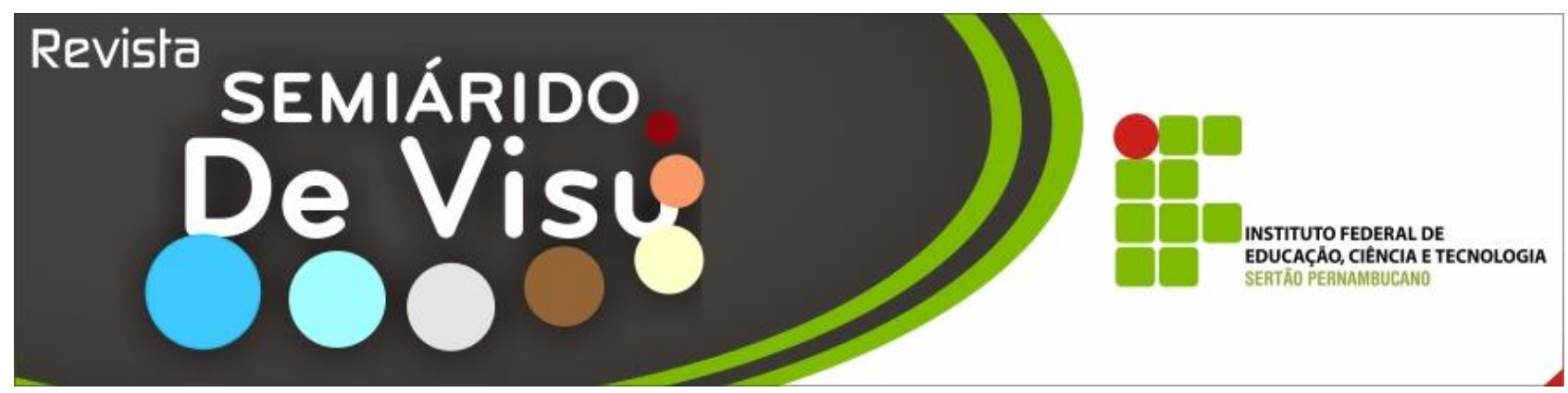

\title{
Utilização do jogo para PC “Age of Empires” como ferramenta didática para aulas de História Antiga
}

\author{
Jean Lúcio Santos Evangelista ${ }^{1}$, Willams Silva Andrade ${ }^{1}$, Ricardo Barbosa Bitencourt ${ }^{1}$, Edivânia \\ Granja da Silva Oliveira ${ }^{1}$
}

${ }^{1}$ Instituto Federal de Educação, Ciência e Tecnologia do Sertão Pernambucano - IF SERTÃO PE, Campus Petrolina, Rodovia BR 407, km 08, s/n, Bairro Jardim São Paulo, CEP: 56.300-000, E-mail: jean.lucio@ ifsertao-pe.edu.br, wsa.juazeiro@gmail.com, ricardo.bitencourt@ifsertao-pe.edu.br, edivania.granja@ifsertao-pe.edu.br

\begin{abstract}
RESUMO: Este artigo é resultado de um trabalho de pesquisa-ação com a implantação do jogo para PC "Age of Empires" como ferramenta didática em aulas de História Antiga. O "Age of Empires" é um jogo de estratégia em tempo-real, ambientado no cenário da História Antiga e lançado para computador em 1997. Ele permite que o gamer controle uma determinada civilização disponível e avance com ela através das Idades da História Antiga, com o objetivo de conquistar outras civilizações ou simplesmente evoluir sua civilização ao grau mais avançado da Era Antiga. Assim este artigo pretende demonstrar o resultado da pesquisa realizada com a implantação deste jogo feita com uma turma de alunos de ensino médio que estudaram História Antiga, buscando avaliar se a utilização deste jogo pode ou não contribuir com o processo de ensino-aprendizagem dos alunos, em relação à disciplina estudada.
\end{abstract}

Palavras-chave: Educação. Novas Tecnologias. Games, Ensino-Aprendizagem.

\section{Using the PC game "Age of Empires" as a teaching tool for classes Ancient History}

\begin{abstract}
This article was scope perform an action research with the implementation of the PC game "Age of Empires" as a teaching tool in classes Ancient History. Age of Empires is a strategy game in real time, set in the backdrop of Ancient History and released for PC in 1997, it allows the gamer to control a particular civilization and go with it available through the Ages of Ancient History, with goal of conquering other civilizations or simply evolve their civilization to the most advanced level of Era Ancient. Thus this paper aims to demonstrate the result of research conducted with the deployment of this game made with a group of high school students who studied Ancient History, trying to assess whether the use of this game may or may not contribute to the process of teaching and student learning, over the course studied.
\end{abstract}

Keywords: Education. New Technologies. Games; Teaching and learning. 
Jean Lúcio Santos Evangelista et al.

\section{Introdução}

$\mathrm{N}$ um mundo cada vez mais imerso em novas tecnologias (computadores, internet, tablets e tantas outras inovações) fica evidente uma verdadeira revolução na forma como o ser humano vive e se organiza. Esses recursos, hoje, especialmente com a popularização da internet, são acessados por uma parcela bastante significativa da população, independentemente de posição socioeconômica, levando-nos a perceber esse acesso como uma necessidade urgente do indivíduo, o que corrobora com os estudos de Abreu et al (2008, p. 159), onde pontua que "a dependência de internet pode ser encontrada em qualquer faixa etária, nível educacional e estrato socioeconômico". Essa dependência, com a disseminação e a produção em larga escala, gerou uma diminuição significativa nos custos de aquisição de tais tecnologias. E hoje é utilizado por uma clientela que cria $\mathrm{e}$ compartilha saberes que, de repente, começam a invadir o cotidiano escolar e colocar em xeque a estrutura rígida do currículo e do fazer didático.

Os jogos eletrônicos ou games estão cada vez mais presentes na vida dos jovens e se faz necessário cada vez mais que as instituições de ensino absorvam essas ferramentas também como instrumentos educacionais. Para se ter uma ideia, uma matéria disponível no site facosite.com afirma que o Brasil é o $4^{\circ}$ maior mercado mundial de jogos digitais; a matéria afirma ainda que os brasileiros "dedicam em média 10,7 horas por semana com o entretenimento. É quase o dobro do tempo destinado a assistir TV (5,5 horas) e se equipara ao índice de 11,3 horas no uso da internet" . Voltando para o uso dos jogos na educação, Alves (2008, p. 8) nos diz que:

A intenção não é transformar as escolas em lan houses, até por que são espaços de aprendizagem diferenciados e com lógicas distintas, mas criar um espaço para os professores identificarem nos discursos interativos dos games, questões éticas, políticas, ideológicas, culturais, etc. que podem ser exploradas e discutidas com os discentes, ouvindo e compreendendo as relações que os jogadores, nossos alunos, estabelecem com estas mídias, questionando, intervindo, mediando a construção de novos sentidos para as narrativas. Ou ainda, aprender com estes sujeitos novas formas de ver e compreender esses artefatos culturais.

Percebe-se no discurso acima que o objetivo não é fazer da escola um espaço de pura diversão e entretenimento, mas sim aliar o ensino com o lúdico, porque a escola pode e deve ser um lugar onde se aprende e onde se sente prazer.

Temos que entender, conforme registra Prensky (2010, p. 61), que "as pessoa que estão sentadas em suas salas de aula cresceram na velocidade acelerada dos videogames e MTV", os seja as crianças de hoje conseguem aprender fazendo várias coisas ao mesmo tempo e a educação tem que se modelar à realidade das crianças de hoje.

\begin{abstract}
Como no passado, maior parte dos pais e professores imigrantes digitais de hoje supõe que 'as crianças são iguais desde sempre' e que 'os mesmos métodos que funcionaram para a educação quando eles eram estudantes vão funcionar para seus alunos agora'. Mas atualmente essas antigas suposições não são mais válidas. Os estudantes de hoje não são mais as pessoas para as quais nosso sistema educacional foi desenvolvido. A maioria dos pais não acreditam que as crianças possam aprender enquanto assistem TV ou ouvem música, só porque eles não conseguem PRENSKY (2010, p. 60 - 61).
\end{abstract}

Neste sentido, observando discussões e a perspectiva de real interesse de crianças e adolescentes por jogos eletrônicos, cabe-nos questionar: é possível a utilização de jogos eletrônicos, ditos não educativos, para ensino ou para apoio ao trabalho pedagógico? Nessa direção, este artigo pretende demonstrar o resultado de uma pesquisa-ação realizada em uma turma de ensino médio, com a utilização do jogo para PC "Age of Empires", jogo ambientado no cenário da História Antiga.

Sobre o estudo da História Antiga podese afirmar que ela é objeto de estudo 
Jean Lúcio Santos Evangelista et al.

fundamental quando se trabalha a disciplina História, tanto para o ensino médio quando para o ensino fundamental. Este período da história é assim definido segundo a Wikipedia:

A História Antiga é um domínio de estudos que se estende desde o aparecimento da escrita cuneiforme (cerca de 4000 a.C.) até a tomada do Império Romano do Ocidente pelos povos bárbaros (476 d.C.). Esse vasto período da humanidade inclui muitas civilizações, não somente na Europa. Nesse período os vários povos influenciaram e também receberam influências fundamentais de outros povos.

Ainda segundo Burns (2005, p.02), o período da História Antiga inicia-se por volta do ano 3.500 a.C, quando surgem as primeiras civilizações avançadas. Afirma o autor que:

Tais civilizações, que alcançaram o conhecimento da escrita e um considerável progresso nas artes e nas ciências, bem como em organização social tiveram origem naquela parte do mundo conhecida como Oriente Próximo. Essa região estende-se do moderno Irã até o Mediterrâneo e a margem ocidental do Nilo. Ali floresceram, em diferentes períodos entre 3000 e 300 a.C., os pujantes impérios dos egípcios, babilônios, assírios, caldeus e persas, juntamente com estados menores, de povos como os hititas, os fenícios e os hebreus.

$\mathrm{O}$ estudo de tal matéria pode ser às vezes difícil para o professor de História, pois, nem sempre alunos costumam se interessar por coisas que aconteceram em uma distância temporal muito grande. Dessa forma, cabe ao professor empenhado em sua missão de ensinar, estar sempre buscando novos métodos e técnicas de ensino para mostrar ao aluno que o ensino de tal conteúdo pode ser fácil e divertido.

Neste contexto surge o uso de novas tecnologias para o ensino e em especial a utilização de jogos eletrônicos ou simplesmente games. Jogos eletrônicos podem ser utilizados pelo professor não em substituição ao conteúdo da disciplina propriamente dita, mas, como

Revista Semiárido De Visu, v.2, n.3, p.338-346, 2012 uma importante ferramenta capaz de auxiliar o professor em sua prática docente. Segundo Frosi e Schlemmer (2012), essa nova geração, propagada como nativos digitais, vive intensamente essa convergência de mídias, o que torna suas utilizações parte da concepção de suas vidas e de seu cotidiano.

Mattar (2009) afirma ainda que:

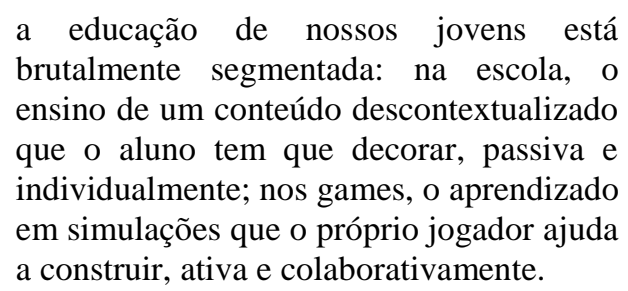

Assim podemos observar a relevância de construir-se nas escolas espaços para implantação de jogos para educação. Defendendo o uso dos games na educação Mattar (2009) diz ainda que:

Jogos podem envolver diversos fatores: cognitivos, culturais, sociais, afetivos, etc. Jogando as crianças aprendem, por exemplo, a negociar em um universo de regras e a postergar o prazer imediato. Então, por que enfrentamos tamanha resistência em relação à utilização de videogames em educação?

A respeito do "Age of Empires" cabe dizer que não existem documentos científicos sobre trabalhos com o citado jogo. Informações levantadas em espaços virtuais na internet revelam que ele faz parte de uma série de jogos eletrônicos para computador e consoles portáteis desenvolvida pela Ensemble Studios e publicada pela Microsoft. O primeiro título da série foi "Age of Empires", lançado em 1997. Depois dele, outros seis títulos da franquia principal e quatro títulos derivados foram lançados. A maior parte da série é formada pelo gênero de estratégia em tempo real, sendo que seus modos de jogo se resumem a dois estilos principais: mapa aleatório e campanha. Além do gênero, os jogos da série são caracterizados por marcarem eventos históricos.

O site Age Mania (http://www.agemania.com.br) é um website brasileiro especializado em todos os jogos da 
Jean Lúcio Santos Evangelista et al.

série "Age of Empires" e derivados, nele podem-se encontrar diversas informações sobre o jogo em comento. Segundo informações do site:

Age of Empires (muitas vezes abreviado para AoE) é baseado em um jogo de estratégia em tempo-real para computador lançado em 1997. Desenvolvido pela Ensemble Studios e publicado pela Microsoft, o jogo usa a placa Genie Game Engine. O jogo permite ao usuário jogar como um líder de uma tribo ou civilização histórica, avançando através de quatro idades (Idade da Pedra, Idade da Ferramenta, Idade do Bronze, e Idade do Ferro).

O jogo em comento permite que o jogador escolha entre uma das doze civilizações disponíveis. Logo no princípio percebemos a relação com eventos históricos, pois, todas as civilizações apresentadas no jogo são baseadas nas civilizações que viveram no período denominado História Antiga.

A partir daí o jogador passa a "desenvolver" esta civilização fazendo com que ela passe por todos os "períodos" da Idade Antiga, coletando recursos, construindo edificações, enfrentando animais selvagens e inimigos ao seu redor. Sagra-se vencedor aquele que consegue desenvolver sua civilização ao ponto máximo permitido no jogo, mais rapidamente que os demais, ou simplesmente que consegue destruir todas as civilizações ao redor.

Uma das principais tarefas do professor ao se trabalhar História Antiga é o de explicar cada uma das civilizações que existiram naquela época, detalhando sua cultura, economia, organização, vida em sociedade, etc. Burns (2005, p.14), ao tratar da temática, levanta alguns questionamentos que devem estar presentes nas discussões entre professores e alunos na sala de aula, tais como: Quais as causas que contribuíram para o aparecimento das civilizações? Por que certas civilizações alcançaram um grau de evolução muito mais alto do que outras? A esses questionamentos o autor declara que:
O esclarecimento dessas questões constitui um dos objetivos principais dos historiadores e dos mais cientistas políticos. Alguns concluem que os fatores geográficos são os mais importantes. Outros põem em relevo os recursos econômicos, as fontes alimentares, o contato com as civilizações mais velhas e assim por diante. Comumente se admitem várias causas, mas em geral os historiadores salientam uma delas como merecedora de ênfase especial.

É interessante notar que jogando "Age of Empires" o aluno pode realizar na prática tudo isso. Desde a escolha do cenário a se jogar (condições geográficas), até a busca por alimentos, a gestão econômica dos recursos armazenados e o completo desenvolvimento da civilização escolhida pelo gamer. E até chegar nesse desenvolvimento final, é possível ainda que a civilização concorrente (seja o computador ou outro usuário conectado ao mesmo jogo) se desenvolva mais cedo ou mais tarde que ele. Quais os critérios que levaram determinada civilização no jogo a se desenvolver mais rapidamente que a outra? E aí voltamos para o estudo da História.

Percebe-se assim, em muitas caraterísticas do jogo, a presença de elementos históricos que se forem adequadamente trabalhados pelo professor em sala de aula podem tornar o ensino da matéria prazeroso para os alunos.

\section{Material e métodos}

A pesquisa em comento foi realizada em uma turma de ensino médio do Instituto Federal de Educação, Ciência e Tecnologia do Sertão Pernambucano, Campus Petrolina. A turma com cerca de 40 alunos já havia estudado a matéria de História Antiga. Incialmente foi feita entrevista com professor e alunos da turma visando identificar métodos de ensino aplicado para o conteúdo de História Antiga. Passada a fase de observação foi sugerido ao docente o uso de jogo "Age of Empires" como ferramenta didática.

Considerando que a pesquisa realizada tinha o propósito de promover uma intervenção 
Jean Lúcio Santos Evangelista et al.

na realidade estudada, acreditamos que ela tratou-se de uma "pesquisa-ação", conforme explica Severino (2007, p. 120):

\begin{abstract}
A pesquisa ação é aquela que, além de compreender, visa intervir na situação, com vistas a modificá-la. O conhecimento visado articula-se a uma finalidade intencional de alteração da situação pesquisada. Assim, ao mesmo tempo que realiza um diagnóstico e a análise de uma determinada situação, a pesquisa-ação propõe ao conjunto de sujeitos envolvidos mudanças que levem a um aprimoramento das práticas analisadas.
\end{abstract}

Tendo sido aceita essa proposta de pesquisa pelo docente e alunos, foi agendada uma data para que os alunos pudessem jogar o game, que ficou disponível no laboratório de informática da escola. Posteriormente, foi aplicado questionário aos alunos visando identificar se o jogo poderia ou não ser usado como ferramenta educacional nas aulas de História Antiga. Ao todo foram realizadas seis questões aos alunos, apenas dezoito alunos da turma puderam participar do Projeto, dos quais quinze responderam ao questionário proposto.

\section{Resultados e discussão}

Como dito anteriormente, dezoito alunos participaram do Projeto de Pesquisaação. Nesta etapa o objetivo foi simplesmente deixar que os alunos jogassem o jogo livremente. Não foi dado nenhum comando a não ser instruções básicas de como jogar e sugestão para aqueles que nunca haviam jogado que começassem pelas primeiras fases e no nível mais fácil.

Os alunos tiveram uma hora e meia de tempo disponível para jogar, somente no outro dia é que foi solicitado que respondessem ao questionário, motivo pelo qual três alunos não responderam, pois, na ocasião não foram localizados. Assim, dos dezoito participantes, quinze responderam ao questionário.

As questões propostas buscavam avaliar se a utilização do "Age of Empires" como ferramenta didática traria benefícios para o processo de ensino-aprendizagem da disciplina de História Antiga. A primeira pergunta do questionário era se os alunos consideravam ser possível aprender conteúdos ministrados em sala de aula através da utilização de jogos e pedia ainda que eles citassem exemplos de jogos que eles acreditavam ser possíveis de utilizar em sala de aula.

Dos quinze entrevistados apenas um não achava ser possível aprender com a utilização de jogos em sala de aula; os demais citaram como exemplos de jogos possíveis de serem utilizados em aula: "GTA, Assassin's Creed, Irmandade, Revelações, Call of Duty 2, Medalha de Honra, Godo $f$ War, Liga da Justiça, Power Ranger, Scooby Doo, Mario, Sonic, Penelope, Monica, PES 2012, Resident Evil, Pedro e sua família, Dota, Comand Conquer". Além dos jogos citados, quatro alunos consideraram o próprio "Age of Empires", que foi experimentado, como um bom jogo para ser utilizado em sala de aula.

Acerca desse primeiro questionamento é interessante notar que quase a totalidade dos alunos entrevistados consideraram ser possível a utilização de jogos em sala de aula, e mais do que isso, citaram exemplos de jogos que na opinião deles podem ser usados. É importante notar que os alunos conseguem fazer essa relação de jogos com educação. Neste primeiro questionamento foi possível observar que jogos e educação não são, ao menos na visão dos alunos, coisas incompatíveis, ambos podem ser conjugados visando melhorar o processo de ensino-aprendizagem.

A segunda pergunta versava sobre se os alunos já conheciam e já haviam jogado o "Age of Empires" antes dessa pesquisa, o gráfico abaixo ilustra o resultado desse questionamento. 
Jean Lúcio Santos Evangelista et al.

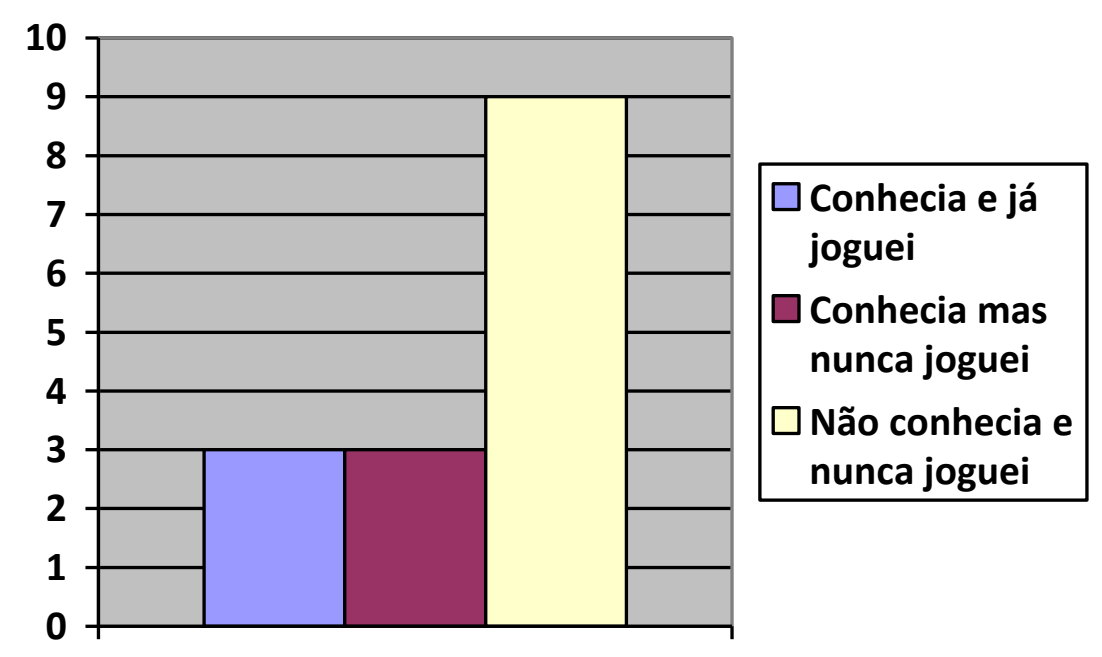

Gráfico 1 - Pergunta se já conhecia e já havia jogado Age of Empires

É possível notar que boa parte dos entrevistados não conhecia até então o jogo, embora, alguns conhecessem e outros inclusive já tivessem jogado. Isso permite afirmar que embora alguns dos entrevistados talvez já tivessem subsídios para considerar ou não o jogo adequado para uso em sala de aula, devido a experiências anteriores com o mesmo, boa parte dos entrevistados (nove) não conhecia o jogo ainda, assim, toda e qualquer opinião que viessem a emitir sobre o mesmo seria com base nas experiências que tiveram na realização desta pesquisa.

Em sequência foi questionado o que eles acharam do nível de dificuldade apresentado no jogo. O resultado segue descrito no gráfico a seguir.

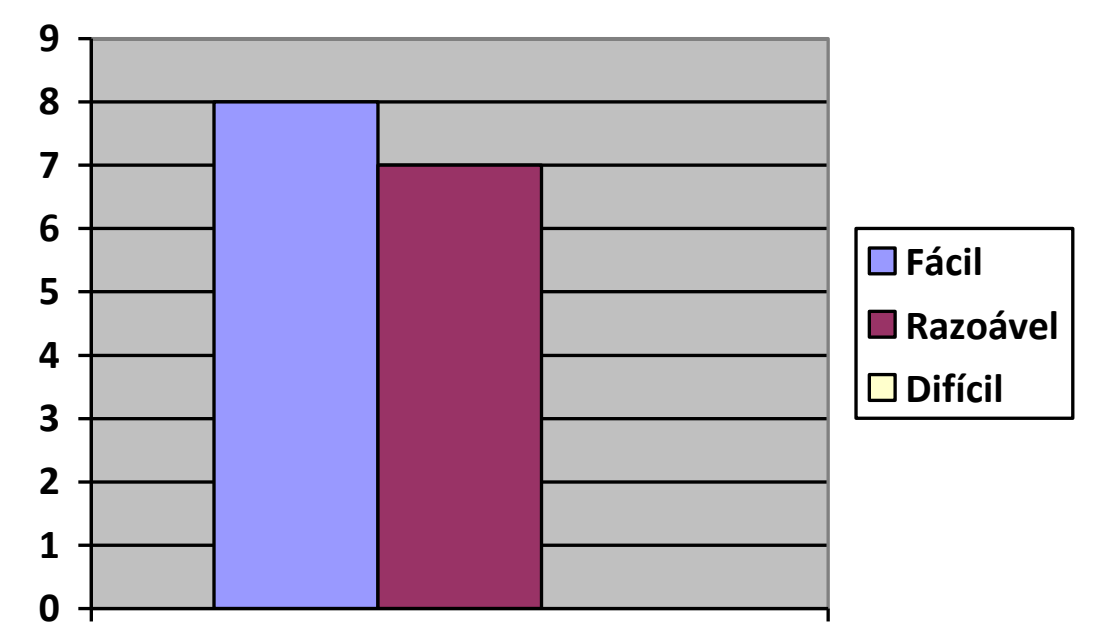

Gráfico 2 - Pergunta sobre o nível de dificuldade do jogo

Essa era uma pergunta importante, pois, o jogo a se trabalhar em sala de aula, não pode apresentar um nível de dificuldade grande, haja vista que assim sendo fugiria ao propósito educacional, assim, foi satisfatório notar que nenhum aluno considerou o jogo difícil, sendo que cerca de metade deles considerou de fácil utilização, enquanto os demais consideraram de utilização razoável, o que demonstra que é 
Jean Lúcio Santos Evangelista et al.

possível utilizar o jogo sem que ele cause dificuldades de uso para os estudantes.

A pergunta que seguiu foi a mais importante da entrevista e questionava se os alunos foram capazes de estabelecer alguma relação do jogo com o que havia sido ministrado pela Professora de História nas aulas sobre História Antiga. A importância desse questionamento advém justamente do objetivo final da pesquisa que era avaliar se este jogo traria algum benefício para $o$ aprendizado na matéria.

Antes, contudo, de se apresentar o resultado obtido é preciso esclarecer alguns pontos. Primeiramente o tempo disponível para que os alunos jogassem foi apenas de uma hora e meia, conforme mencionado anteriormente. Tal tempo embora permitisse a utilização de algumas fases do jogo, não permitia a exploração do mesmo em sua totalidade, principalmente porque as fases iniciais destinam-se a "ensinar" ao gamer os comandos do jogo, apresentando por vezes algumas limitações para a sua correlação com a disciplina História.

Ademais é preciso considerar que os alunos embora tivessem estudado a matéria História Antiga, isso já havia acontecido há alguns meses, assim o melhor aproveitamento do jogo se daria se ele tivesse sido aplicado concomitantemente à ministração da disciplina.

Contudo, como resultado desse questionamento teve-se que seis alunos afirmaram que não conseguiram estabelecer uma relação do jogo com a matéria História Antiga contra nove que afirmaram terem conseguido fazer esta relação.

Dos nove alunos que conseguiram estabelecer essa relação foram questionados ainda exemplos de coisas presentes no jogo que eles conseguiram relacionar com a disciplina. Foram citados por eles aspectos como "organização da sociedade", "a época, a forma com que eles vivam e conseguiam as coisas", "homens pré-históricos, civilizações", "civilizações antigas", "conhecer como era a sobrevivência confeccionando as próprias armas e indo em busca de suas necessidades", "o sistema de conquista e a relação entre civilizações", "a evolução humana".

De fato, todas estas coisas estão presentes no estudo de História Antiga e puderam ser identificadas pelos alunos que jogaram o jogo. Interessante notar que não foi dada aos alunos nenhum resposta pronta para que fosse assinalada, todas estas citações foram feitas livremente pelos mesmos que conseguiram relacionar fatos que foram estudados em sala de aula com o que foi explorado no jogo.

Como havia sido dito anteriormente o "Age of Empires" permite que o jogador escolha uma civilização e a controle, evoluindo através dos períodos históricos, conquistando outras civilizações com o objetivo de vencer o jogo. Isso foi identificado pelos alunos que jogaram, como elementos estudados na disciplina, assim chega-se ao ponto em que é possível verificar que o "Age of Empires" pode ser utilizado com êxito nas aulas de História Antiga, por trazer de maneira lúdica eventos que até então só são estudados muitas vezes através dos livros.

A seguir uma pergunta bastante salutar também questionava ao aluno se ele considerava ser possível aprender melhor os eventos históricos estudados na disciplina História Antiga com a utilização do jogo "Age of Empires". Este quesito quase que unanimemente foi respondido positivamente, apenas um entrevistado não considerou ser possível aprender com o jogo, os outros quatorze consideraram sim ser possível e justificaram. Entre as respostas dadas muitas apontavam para o fato de com o jogo eles podiam simular como era a vida da sociedade em estudo. Outros afirmaram ainda que era possível através do jogo compreender melhor os fatos históricos e assim ter um melhor aprendizado da matéria.

A resposta a este quesito serviu para reforçar a tese de que o jogo "Age of Empires" pode ser usado com êxito em sala de aula, vez que desperta o interesse do aluno através de uma forma de aprendizagem mais dinâmica e divertida. A última pergunta da entrevista versava sobre se o aluno havia gostado de jogar 
Jean Lúcio Santos Evangelista et al.

"Age of Empires". Mais uma vez teve-se como resultado que quatorze alunos afirmaram terem gostado, contra apenas um que disse não ter gostado do jogo. Esse resultado demonstra que o jogo é agradável e pode ser implantado em sala de aula, pois, em tese, atrairá o interesse da maioria dos estudantes e promoverá uma forma divertida e eficiente de se aprender a matéria

\section{Conclusão}

Diante dos resultados obtidos na pesquisa pode-se concluir que o "Age of Empires" é um jogo que pode ser implantado em sala de aula, na disciplina de História, visando auxiliar o docente no ensino da matéria História Antiga. Tal jogo pode trazer, como foi visto, inúmeras contribuições para o processo de ensino-aprendizagem do aluno e certamente se aplicado de maneira adequada se tornará uma ferramenta eficaz de aprendizagem desta matéria.

É preciso ressaltar que esta pesquisa teve como intuito verificar a possibilidade de implantação deste jogo especificamente e qual a reação dos alunos que puderam participar desta experiência. Observou-se ao longo da pesquisa que os alunos se divertiam muito jogando e que boa parte deles puderam fazer uma relação com o que foi estudado, podendose concluir que efetivamente o jogo pode ser aplicado como ferramenta didática.

Além disso, outros jogos desta série, até mesmo sobre outras temáticas, podem ser estudados e aplicados como ferramentas didáticas. Como foi dito no início deste artigo, é crescente a participação mundial do Brasil no mercado de games $e$ a implantação destes jogos nas escolas deixa de ser uma opção e passa a ser uma obrigação dos profissionais de educação preocupados com a modernização do ensino no país.

\section{Agradecimentos}

Ao IF SERTÃo PE, que cedeu espaço para realização da pesquisa, bem como laboratório de informática onde o Projeto foi efetivamente desenvolvido. Também aos alunos que participaram da pesquisa.

\section{Referências}

ABREU, Cristiano Nabuco de; KARAM, Rafael Gomes; GOES, Dora Sampaio and SPRITZER, Daniel Tornaim. Dependência de Internet e de jogos eletrônicos: uma revisão. Rev. Bras. Psiquiatr. [online]. 2008, vol.30, n.2, pp. 156-167. ISSN 1516-4446.

\section{Age of Empires: Microsoft, 1997. 1 CD ROM}

ALVES, Lynn (2008). Relações entre os jogos digitais e aprendizagem: delineando percurso. In Educação, Formação \& Tecnologias; vol.1(2); pp. 3-10, Novembro de 2008, disponível no URL: http://eft.educom.pt.

(2004) Game over: jogos eletrônicos e violência, no Estado da Bahia. Salvador: PPGE/UFBA, 2004. Disponível em: http://www.lynn.pro.br/admin/files/lyn_artigo/ 685ef5af57.pdf

ANDRADE, Luiz Adolfo de. Espaço, jogos e comunicação: rumos para cultura transmidia. Ciberlegenda (UFF. Online), v. 25, p. 1, 2012.

BUREAU DE INSPIRAÇÃO. Disponível em: http://www.facosite.com.br/2011/05/03/com35-milhoes-de-usuarios-brasil-e-4\%C2\%BAmaior-mercado-de-jogos-digitais/. Acesso em 15 out. 2012

BURNS, Edward McNall. História da civilização ocidental: do homem das cavernas v. 1. 44. ed. - São Paulo: Globo, 2005.

FROSI, Felipe O. SCHLEMMER, Eliane. Jogos Digitais no Contexto Escolar: desafios e possibilidades para a Prática Docente. IX SBGames - Florianópolis - SC, 8 a 10 de Novembro de 2010. Disponível em: http://www.sbgames.org/papers/sbgames 10/cul ture/full/full13.pdf Acessado em: 01/10/2012. 
Jean Lúcio Santos Evangelista et al.

História Antiga. In: WIKIPÉDIA: a

enciclopédia livre. Wikimedia, 2012.

Disponível em:

http://pt.wikipedia.org/wiki/Hist\%C3\%B3ria_

Antiga. Acesso em 29 set. 2012.

PRENSKY, Mark. Não me atrapalhe, mãe - Eu estou aprendendo. São Paulo: Editora Phorte, 2010.

SEVERINO, Antônio Joaquim. Metodologia do trabalho científico. 23 ed. rev. e atual. - São Paulo: Cortez, 2007. 